\title{
Evaluation Of Clinical Parameters Related To Methotrexate Therapy In Lichen Planus.
}

\author{
Samaresh Chandra Hazra ${ }^{1}$, Agha Masood Choudhury², Lubna Khondker ${ }^{3}$, Md Shirajul Islam Khan ${ }^{4}$, Muhammad \\ Munir Rashid ${ }^{5}$ \\ ${ }^{1}$ Medical officer, Infectious Diseases Hospital, Mohakhali, Dhaka; ${ }^{2}$ Chairman and Professor, ${ }^{3}$ Assistant professor, ${ }^{5}$ Associate professor, Department of \\ Dermatology and Venereology, Bangabandhu Sheikh Mujib Medical University (BSMMU), Dhaka; ${ }^{4}$ Graded specialist, Department of Dermatology \\ and Venereology, CMH, Dhaka, Bangladesh.
}

\begin{abstract}
:
Background: For better management of lichen planus a clinical trial of oral methotrexate is necessary in our country. Objective: The objective of this study is to evaluate efficacy and safety of methotrexate therapy in the treatment of lichen planus. Methods: It was a prospective randomized controlled clinical trial conducted in the department of Dermatology and Venereology, BSMMU, Dhaka, from January 2009 to December 2010. Forty four patients of lichen planus were included in the study. Cases (group- $A, n=23)$ were treated with methotrexate $(10 \mathrm{mg})$ single morning dose and control (group- $\mathrm{B}, \mathrm{n}=21$ ) were treated with mini pulse betamethasone $(5 \mathrm{mg})$ single morning dose on 2 consecutive days during the period of 12 weeks. Results: Clinical parameters were measured by follow up clinical examination. Morphological lesion of lichen planus improved $95.7 \%$ in group-A and only $28.6 \%$ improved in group-B. At the end of study $82.6 \%$ had no complaints of itching in group-A and $100 \%$ had no complaints of itching in group-B. 16(69.6\%) patients in group-A were completely cured clinically but $10(47.6 \%)$ in group-B. Anemia $3(14.2 \%)$ and edema $12(57.1 \%)$ developed in group-B but none in group-A. In group-B, dyspepsia $15(71.4 \%)$, acne $10(47.6 \%)$, mooning face $8(38.1 \%)$, striae $8(38.1 \%)$ and hypertrichosis $4(19.0 \%)$ developed but none in group-A. Intermittent diarrhoea, headache, nausea and fatigue complained in both groups of patients but the percentage of complaints was higher amog group-B compared to group-A. Menstrual abnormality developed in group-B $5(71.4 \%)$ but none in group-A. Conclusion: The overall adverse effects were less in group-A than group-B. Therefore, methotrexate can be used as an alternative safer option for the treatment of lichen planus.
\end{abstract}

Key words: Lichen planus, clinical parameter of methotrexate therapy.

[BSMMUJ $2013 ; 6(2): 90-98]$

\section{Introduction:}

Lichen planus is an inflammatory mucocutaneous disease characterized by shiny, violaceous, polygonal, flat topped, firm papules and plaques with Wickham's striae on the surfaces of lesions $^{1}$. It is highly pruritic ${ }^{2}$. T cells become activated via antigen-presenting cells such as Langerhans cells in conjunction with epidermal keratinocytes and co-stimulatory molecules. These activated T lymphocytes play a pivotal role in regulating epidermal cell recognition, the lichenoid response and basal cell damage. Lichen planus is an unpredictable disease that typically persists for 1 to 2 years, but may follow a chronic, relapsing

Address for Correspondence: : Dr Samaresh Chandra Hazra Medical officer, Infectious Diseases Hospital, Mohakhali, Dhaka.

E-mail:samohazra@yahoo.com. course over many years ${ }^{3}$. Lichen planus may cause atrophic cicatricial alopecia and nail dystrophy with the involvement of scalp and nail respectively ${ }^{4}$. Skin lesions of lichen planus may be disfiguring. Involvement of the oral and genital mucosa in severe cases may be debilitating. Oral lichen planus may predispose to the development of squamous cell carcinoma within the lesions ${ }^{1}$. Methotrexate is the most commonly dermatologistprescribed oral immunosuppressive agents ${ }^{5}$. Methotrexate is mainly related to its effect on epidermal cell proliferation. It has a more significant effect on lymphoid cells. Methotrexate has anti-inflammatory effects and its anti-inflammatory effects exerts via inhibition of lymphocyte proliferation. So methotrexate can be a highly effective treatment alternative to systemic corticosteroid and 
other systemic drugs in the treatment of lichen planus ${ }^{21}$. Topical corticosteroids are widely used as first-line treatment, but response often incomplete ${ }^{14}$. Topical treatment is impractical and patient compliance is poor for patients with generalized lichen planus ${ }^{21}$. Oral corticosteroids result in prompt improvement but relapse is common as the dose is reduced ${ }^{25}$ and it is related with many sideeffects. These side effects of systemic steroids are unavoidable $^{26}$. But methotrexate is well tolerated, convenient dose schedule, easily available, cheap and local made with mild to moderate gastrointestinal, hepatic, renal and hematological side effects that can be deceted by clinical examination and laboratory investigations and take measures to prevent it by adding folic acid and reduce the dose. So, methotrexate can be a highly effective and tolerable treatment alternative to systemic corticosteroid in the treatment of lichen planus ${ }^{6}$.

Treatment of lichen planus is difficult and a lack of randomized controlled clinical trial makes evaluation of therapies challenging ${ }^{6}$. For safer treatment option a prospective, randomized controlled clinical trial of oral methotrexate is necessary in our country, to find out an alternative safer drug for the treatment of lichen planus.

\section{Methods:}

A prospective randomized controlled clinical trial was conducted in the department of Dermatology and Venereology, Bangabandhu Sheikh Mujib Medical University (BSMMU), Dhaka, Bangladesh. The patients of lichen planus attending at the department of Dermatology and Venereology, during the period of January 2009 to December 2010 were enrolled in this study. Total 44 patients were enrolled following inclusion and exclusion criteria. Of them 23 patients in group-A (case) and 21 patients in group-B (control) were selected randomly. A data collection sheet was used for research instrument.

Both male and female patients having 18 years or more, clinically and histopathologically diagnosed lichen planus and baseline investigatios such as $\mathrm{CBC}$, liver and renal functions tests were normal and willng to participate in this study were selected as our study patients. After exclusion of co-morbidity (acute infection, diabetes mellitus, uncontrolled hypertension, neoplasia, hepatic, renal and haematological diseases), pregnancy and lactation, the selected patients were finally included as our study participants.
Patients reported as lichen planus clinically and histopathologically at BSMMU and followig inclusion and exclusion criteria were selected for study. History, clinical examination and baseline haematological and biochemical test of blood (CBC, Liver and renal function tests, Random plasma glucose) were done before intervention. Group-A patients were given oral methotrexate $10 \mathrm{mg}$ (Tab. Methotrax $10 \mathrm{mg}$ ) single morning dose after breakfast once in a week and oral folic acid $5 \mathrm{mg}$ (Tab. Folison $5 \mathrm{mg}$ ) single morning dose after breakfast on the next day of methotrexate dose for 12 weeks. Group-B patients were given oral betamethasone $5 \mathrm{mg}$ (Tab. Betnelan $0.5 \mathrm{mg}, 10$ tablets at a time) in a single morning dose after breakfast on 2 consecutive days of every week for 12 weeks.

Patients were followed up for clinical improvement and adverse effects of therapy at $1^{\text {st }}, 2^{\text {nd }}, 6^{\text {th }}$ and $12^{\text {th }}$ week. Efficacy and adverse effects of drugs were recorded as patient complaints and clinical evaluation. Patients were monitored by physical and dermatological examinations, and laboratory investigations such as CBC and SGPT weekly for first 2 weeks, then after 6 weeks and 12 weeks. The treatment with methotrexate was stopped if total count of $\mathrm{WBC}<4000 / \mathrm{cu} \mathrm{mm}$ or platelet count < $100,000 / \mathrm{cu}$ mm of blood or SGPT exceeded 3 times of the upper limit of normal value. When WBC, platelet count and SGPT were returned to normal methotrexate was started at a lower dose. Photographs of lesions at baseline and then after 6 weeks and 12 weeks were taken for subsequent assessment and compare.

After collection, data was checked for inadequacy, irrelevancy, and inconsistency. All data was analyzed with appropriate statistical tools and SPSS 15 program and presented as text, tables and figure.

\section{Results:}

Total 44 patients with complete data were included in the study. The mean age of group- $\mathrm{A}(\mathrm{n}=23)$ was $34.9( \pm 13.4)$ years ranging from 18 to 60 years, whereas the mean age of group-B $(\mathrm{n}=21)$ was $32.9( \pm 11.4)$ years ranging from 18 to 61 years, but the mean difference was not statistically significant ( $p>0.05$ ), though the mean age of group-A was higher than group-B. No statistically significant sex difference was found between group-A and group-B ( $p>0.05$ ), though the proportion of male patients were higher in group-A 9 (39.1) compared to group-B 7 (33.3) (Table-I). 
All the patients had skin lesion, but $19(43.2 \%)$ had lesion in mucous membrane and $10(22.7 \%)$ had nail and 3 $(6.8 \%)$ had lesion in hair follicle. The mean duration of disease was $18.7( \pm 4.0)$ months for the group-A and 17.5 $( \pm 5.6)$ months for group-B. But the mean difference was not statistically significant $(\mathrm{p}>0.05)$ (Table-II).
Data showed that the proportion of macular, popular and plaque was found to be high among group-B 8(38.1\%) compared to group-A 5(21.7\%). On the contrary, popular and plaque was found to be high among group- $\mathrm{A}$ $17(73.9 \%)$ than group-B $12(57.1 \%)$, but the difference was not statistically significant $(\mathrm{p}>0.05)$ (Table-III).

Table-I

Distribution of the patients by age and sex in both groups

\begin{tabular}{lllll}
\hline Characteristics & Group $-\mathrm{A}(\mathrm{n}=23)$ & Group $-\mathrm{B}(\mathrm{n}=21)$ & Total(n=44) & P value \\
\hline Age in years & $\mathrm{n}(\%)$ & $\mathrm{n}(\%)$ & $\mathrm{n}(\%)$ & \\
$<25$ & $6(26.1 \%)$ & $4(19.0 \%)$ & $10(22.7 \%)$ & \\
$25-34$ & $6(26.1 \%)$ & $9(42.9 \%)$ & $10(34.1 \%)$ & \\
$35-44$ & $5(21.7 \%)$ & $5(23.8 \%)$ & $5(11.4 \%)$ & \\
$45-54$ & $4(17.4 \%)$ & $1(4.8 \%)$ & $4(9.1 \%)$ & 0.596 \\
$\geq 55$ & $2(8.7 \%)$ & $2(9.5 \%)$ & $33.9( \pm 12.4)$ & \\
Mean $( \pm \mathrm{SD})$ & $34.9( \pm 13.4)$ & $32.9( \pm 11.4)$ & $18-61$ & \\
Range & $18-60$ & $18-61$ & & \\
Sex & & $14(66.7 \%)$ & $28(63.6 \%)$ & \\
Female & $14(60.9 \%)$ & $7(33.3 \%)$ & $16(36.4 \%)$ & \\
Male & $9(39.1 \%)$ & & & \\
\hline
\end{tabular}

$€=p$ value reached from unpaired student's $t$ test and other $p$ value reached from Chi square test

Table-II

Distribution of patients by site of involvement and duration of disease.

\begin{tabular}{|c|c|c|c|c|}
\hline Characteristics & Group $-\mathrm{A}(\mathrm{n}=23)$ & Group $-\mathrm{B}(\mathrm{n}=21)$ & Total $(n=44)$ & $\mathrm{p}$ value \\
\hline Site of 1 esion & $\mathrm{n} \quad(\%)$ & $\mathrm{n}(\%)$ & $\mathrm{n} \quad(\%)$ & \\
\hline Skin & $23(100.0 \%)$ & $21(100.0 \%)$ & $44(100.0 \%)$ & \\
\hline Mucous membrane & $8(34.8 \%)$ & $11(52.4 \%)$ & $19(43.2 \%)$ & \\
\hline Nail & $4(17.4 \%)$ & $6(28.6 \%)$ & $10(22.7 \%)$ & \\
\hline Hair follicle & $3(13.0 \%)$ & $0(.0 \%)$ & $3(6.8 \%)$ & \\
\hline $\begin{array}{l}\text { Mean duration of } \\
\text { disease (months) }\end{array}$ & $18.7( \pm 4 \quad .0)$ & $17.5( \pm 5.6)$ & $17.9( \pm 3.4)$ & $\mathrm{p}>0.05$ \\
\hline
\end{tabular}


During follow up of the patients, it was found that $95.7 \%$ of the lesion became macule treated by oral methotrexate and only $28.6 \%$ became macule treated by betamethasone oral mini- pulse. At the end of follow up, $4.3 \%$ had papule and no patient had plaque among the group- $\mathrm{A}$, whereas $61.9 \%$ had papule and $4.8 \%$ had plaque in group-B and the difference was statistically significant $(\mathrm{p}<0.05)$ (Table III).

Considering the color changes, initially $91.3 \%$ of the group-A and $90.5 \%$ of group-B had violaceous color but no statistically significant difference was found between two groups of patients $(p>0.05)$. But at the end of $12^{\text {th }}$ week follow up, $95.7 \%$ in the group-A became post inflammatory hyper pigmentation and it was $85.7 \%$ in the group-B and $14.3 \%$ still have erythematous color group-B. Only $4.3 \%$ of the group-A had erythematous color. However, analysis did not show any statistically significant difference between two groups of patients $(\mathrm{p}>0.05)$ (Table IV).

Table-III

Comparative studies of patient's improvement by morphological changes 0 flesions during the $12^{\text {th }}$ week follow up period

\begin{tabular}{llll}
\hline $\begin{array}{l}\text { Clinical Presentation } \\
\text { Baseline }\end{array}$ & $\mathrm{n}(\%)$ & $\mathrm{n}(\%)$ & \\
\hline $\begin{array}{l}\text { Macule, papule } \\
\text { and plaque }\end{array}$ & $5(21.7 \%)$ & $8(38.1 \%)$ & $\mathrm{p}>0.05$ \\
$\begin{array}{l}\text { Macule and papule } \\
\text { Plaque }\end{array}$ & $17(73.9 \%)$ & $12(57.1 \%)$ & \\
6th wk & $1(4.3 \%)$ & $1(4.8 \%)$ & \\
Maculae & $5(21.7 \%)$ & $3(14.3 \%)$ & $\mathrm{p}>0.05$ \\
Macule and papule & $7(30.4 \%)$ & $5(23.8 \%)$ & \\
Papule & $11(47.8 \%)$ & $12(57.1 \%)$ & \\
Plaque & 0.0 & $1(4.8 \%)$ & \\
$\begin{array}{l}\text { 12th wk } \\
\text { Maculae }\end{array}$ & $22(95.7 \%)$ & $6(28.6 \%)$ & $\mathrm{p}<0.05$ \\
Macule and papule & 0.0 & $1(4.8 \%)$ & \\
Papule & $1(4.3 \%)$ & $13(61.9 \%)$ & \\
Plaque & 0.0 & $1(4.8 \%)$ & \\
\hline
\end{tabular}

Regarding complaints of itching, initially $4.3 \%$ of group-A had complaints of mild itching and $14.3 \%$ in group-B. However, $65.2 \%$ of group-A had severe itching and $71.2 \%$ had severe itching group- $\mathrm{B}$. At the end of $12^{\text {th }}$ week follow up, $82.6 \%$ had no complaints of itching in
group-Aand no patient had complaints of itching among group-B. But the difference was not statistically significant $(\mathrm{p}>0.05)$ (Table V).

\section{Table-IV}

Comparative studies of patient's improvement by changes of colour of lesions from baseline to $12^{\text {th }}$ week follow up period

Clinical presentation Group- $A(n=23)$ Group- $B(n=21) p$ value

\begin{tabular}{|c|c|c|c|}
\hline Baseline & n $(\%)$ & n $\quad(\%)$ & \\
\hline Violaceous & $21(91.3 \%)$ & $19(90.5 \%)$ & \multirow[t]{4}{*}{$p>0.05$} \\
\hline Erythematous & \multirow[t]{3}{*}{$2(8.7 \%)$} & \multirow[t]{3}{*}{$2(9.5 \%)$} & \\
\hline and Violaceous & & & \\
\hline 6th wk & & & \\
\hline Postinflammatory & \multirow[t]{2}{*}{$5(21.7 \%)$} & \multirow[t]{2}{*}{$9(42.9 \%)$} & \multirow[t]{7}{*}{ - } \\
\hline hyperpigmentation & & & \\
\hline Erythematous & $14(60.9 \%)$ & $10(47.6 \%)$ & \\
\hline Violaceous & $3(13.0 \%)$ & $2(9.5 \%)$ & \\
\hline Erythematous & \multirow[t]{3}{*}{$1(4.3 \%)$} & \multirow[t]{3}{*}{.0} & \\
\hline and Violaceous & & & \\
\hline 12th wk & & & \\
\hline Postinflammatory & \multirow[t]{2}{*}{$22(95.7 \%)$} & \multirow[t]{2}{*}{$18(85.7 \%)$} & \multirow[t]{3}{*}{$\mathrm{p}>0.05$} \\
\hline hyperpigmentation & & & \\
\hline Erythematous & $1(4.3 \%)$ & $3(14.3 \%)$ & \\
\hline
\end{tabular}

Table-V

Distribution of the improvement of severity of itching from baseline to $12^{\text {th }}$ week follows up period Group- $\mathrm{A}(\mathrm{n}=23)$ Group-B(n=21)

\begin{tabular}{lll} 
Baseline & $\mathrm{n}(\%)$ & $\mathrm{n}(\%)$ \\
\hline Mild & $1(4.3 \%)$ & $3(14.3 \%)$ \\
Moderate & $7(30.4 \%)$ & $3(14.3 \%)$ \\
Severe & $15(65.2 \%)$ & $15(71.4 \%)$ \\
1st wk & & \\
Mild & $3(13.0 \%)$ & $5(23.8 \%)$ \\
Moderate & $8(34.8 \%)$ & $12(57.1 \%)$ \\
Severe & $12(52.2 \%)$ & $4(19.0 \%)$ \\
2nd wk & & $5(23.8 \%)$ \\
No & .0 & $12(57.1 \%)$ \\
Mild & $5(21.7 \%)$ & $4(19.0 \%)$ \\
Moderate & $12(52.2 \%)$ & .0 \\
Severe & $6(26.1 \%)$ & \\
6th wk & & $20(95.2 \%)$ \\
No & \multicolumn{2}{c}{$3(13.0 \%)$}
\end{tabular}




\begin{tabular}{lll} 
Baseline & $\begin{array}{l}\text { Group-A(n=23) } \\
\mathrm{n}(\%)\end{array}$ & $\begin{array}{l}\text { Group-B(n=21) } \\
\mathrm{n}(\%)\end{array}$ \\
\hline Mild & $17(73.9 \%)$ & $1(4.8 \%)$ \\
Moderate & $3(13.0 \%)$ & .0 \\
12th wk & & \\
No & $19(82.6 \%)$ & $21(100.0 \%)$ \\
Mild & $4(17.4 \%)$ & .0 \\
\hline
\end{tabular}

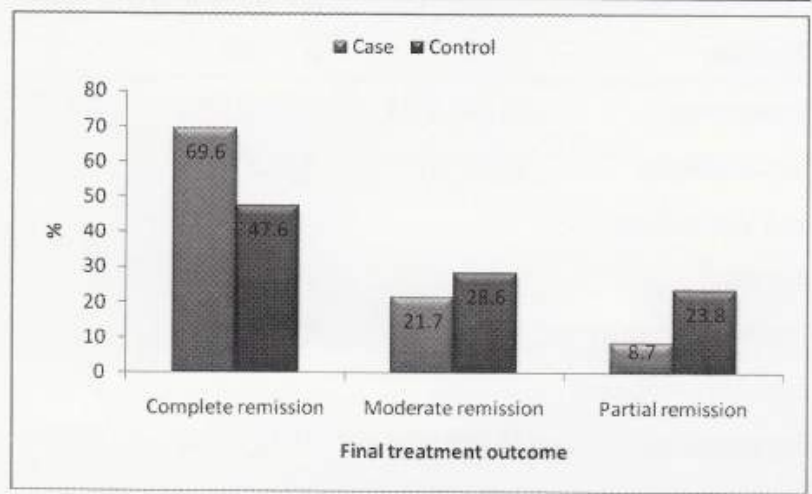

Fig-1: Distribution of treatment outcome of two groups of patients

In figure 1, it was found that complete remission of the disease was occurred in $69.6 \%$ among group- $\mathrm{A}$, whereas it was $47.6 \%$ among group- $\mathrm{B}$. The moderate remission was $28.6 \%$ in group-B and $21.7 \%$ in group-A and partial remission was $23.8 \%$ in group-B and $8.7 \%$ in group-A, which were higher among group-B compared to group-A. However, analysis did not revealed any statistically significant difference between two treatment modalities $(\mathrm{p}>0.05)$.

Table VI revealed that none of group-A had developed anemia and edema in subsequent follow up. However, $3(14.2 \%)$ patients in group-B developed anemia and 12 $(57.1 \%)$ of the patients in group-B developed edema during $12^{\text {th }}$ week follow up $(\mathrm{p}<0.05)$. Analysis revealed that the mean change of body weight was noticed from baseline to $12^{\text {th }}$ week follow up. Body weight increased in group-A from $55.9( \pm 2.4)$ to $56.5( \pm 2.4)$ and in group-B from $58.7( \pm 2.6)$ to $61.5( \pm 2.5)$. Mean difference of body weight was found between group- $A$ and group- $B(p<0.05)$ indicating mean body weight increased in group-B compared to group-A.

Adverse clinical symptoms like diarrhea, nausea, headache, alopecia and fatigue developed in both groups of patients during follow up period. The percentages of complaints were found to be higher among group-B compared to group-A, but the difference was not statistically significant $(p>0.05)$ between two groups of patients. Dyspepsia developed in group-A $11(47.8 \%)$, but in group-B $15(71.4 \%)$. Statistically significant difference was found between two groups of patients $(\mathrm{p}<0.05)$ (Table VI).

Table VI also revealed that among group-A, none developed acne, mooning face and striae from baseline to follow up period. But among group-B, acne 10(47.6\%), mooning face $8(38.1 \%)$ and striae $8(38.1 \%)$ developed during the follow up period. Statistically significant difference was found between two groups of patients $(\mathrm{p}<0.05)$.

Among group-A, none developed purpura and hypertrichosis from baseline to follow up period but among group-B purpura $2(9.5 \%)$ and hypertrichosis $4(19.0 \%)$ developed during follow up period. On the contrary, mouth ulcer developed in both groups of patients during follow up. However, no statistically significant difference was found between two groups of patients ( $p>0.05$ ) (Table VI).

Among the female patients, initially none complained of menstrual abnormality among both groups of patients but during follow up period, menstrual abnormality developed in group-B 5(71.4\%) and none developed menstrual abnormality among groip-A(Table VI). 
Table-VI

Comparative study of the adverse effects (symptoms \& signs) of the patients during 12 weeks follows up period.

Characteristics Group- $\mathrm{A}(\mathrm{n}=23)$ Group- $\mathrm{B}(\mathrm{n}=21)$ p value
n $\%$
n $\%$

\begin{tabular}{|c|c|c|c|}
\hline Anemia & 0 & $3(14.2 \%)$ & $\mathrm{p}<0.05$ \\
\hline Edema & 0 & $12(57.1 \%)$ & $\mathrm{p}<0.05$ \\
\hline \multicolumn{4}{|l|}{ Weight in $\mathrm{kg}$} \\
\hline Baseline & $55.9(+2.4)$ & $58.7(+2.6)$ & $\mathrm{p}<0.05$ \\
\hline $12^{\text {th }}$ week & $56.5(+2.4)$ & $61.5(+2.6)$ & $\mathrm{p}<0.05$ \\
\hline Diarrhoea & $3(13.04)$ & $2(9.52 \%)$ & $\mathrm{p}>0.05$ \\
\hline Nausea & $7(30.4 \%)$ & $7(33.3 \%)$ & $\mathrm{p}>0.05$ \\
\hline Dyspepsia & $11(47.8 \%)$ & $15(71.4 \%)$ & $\mathrm{p}<0.05$ \\
\hline Headache & $6(26.1 \%)$ & $7(33.3 \%)$ & $\mathrm{p}>0.05$ \\
\hline Alopecia & $4(17.4 \%)$ & $1(4.8 \%)$ & $\mathrm{p}>0.05$ \\
\hline Fatigue & $8(34 . .8 \%)$ & $11(52.4 \%)$ & $\mathrm{p}>0.05$ \\
\hline Acne & 0.0 & $10(47.6 \%)$ & $\mathrm{p}<0.05$ \\
\hline Mooning face & 0.0 & $8(38.1 \%)$ & $\mathrm{p}<0.05$ \\
\hline Striae & 0.0 & $8(38.1 \%)$ & $\mathrm{p}<0.05$ \\
\hline Purpura & 0.0 & $2(9.5 \%)$ & $p>0.05$ \\
\hline Hypertrichosis & 0.0 & $4(19.0 \%)$ & $p>0.05$ \\
\hline Mouth ulcer & $3(13.0 \%)$ & $2(9.5 \%)$ & $\mathrm{p}>0.05$ \\
\hline $\begin{array}{l}\text { Menstrual } \\
\text { abnormality }\end{array}$ & 0.0 & $5(71.4 \%)$ & $\mathrm{p}<0.05$ \\
\hline
\end{tabular}

$\mathrm{p}$ value reached from Fisher's exact test

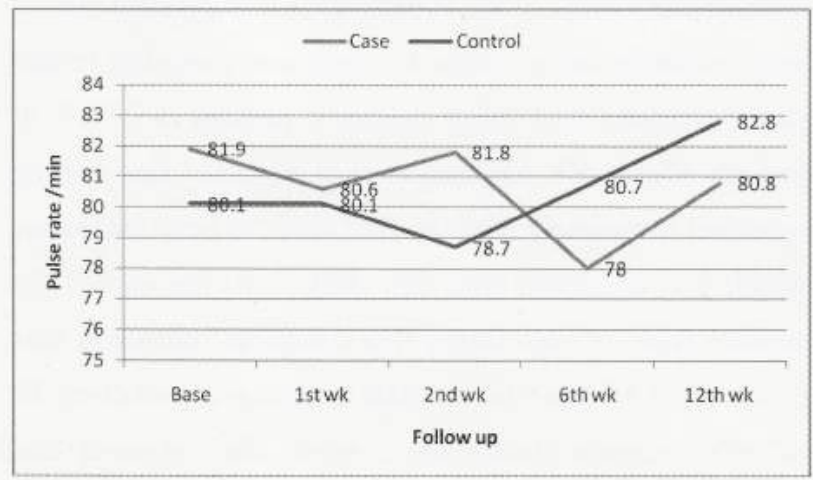

Fig-2: Mean pulse rate at different follow up period

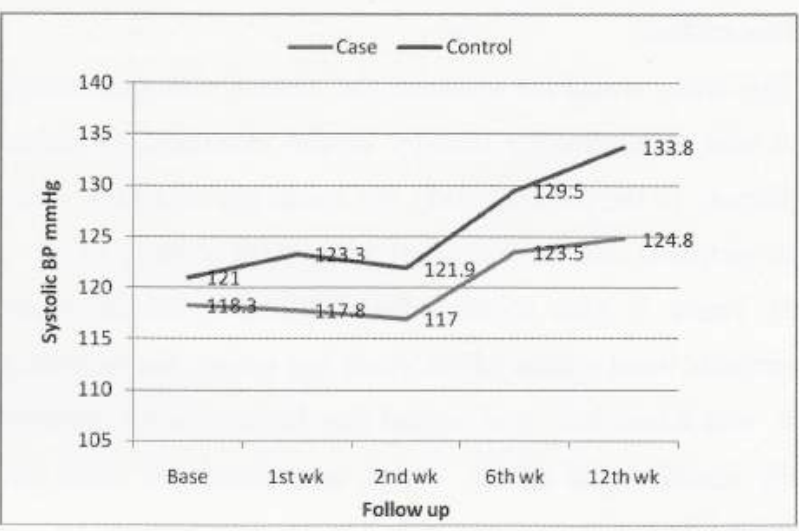

Fig-3: Mean systolic blood pressure at different follow up period.

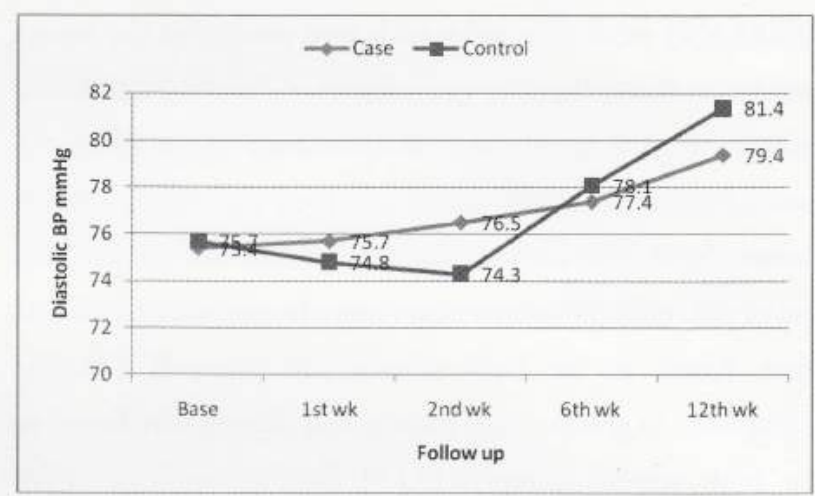

Fig-4: Mean diastolic blood pressure at different follow up period

Figure II, III, IV showed the follow up of mean distribution of pulse rate, systolic blood pressure and diastolic blood pressure. Independent sample t test (unpaired student's t test) revealed that no statistically significant mean difference was found between group-A and group-B in terms of pulse rate at the different follow up period $(\mathrm{p}>0.05)$. Repeated measure analysis of variance indicated that no statistically significant mean difference was found between baseline to $1^{\text {st }}, 1^{\text {st }}$ to $2^{\text {nd }}, 2^{\text {nd }}$ to $3^{\text {rd }}$ and $3^{\text {rd }}$ to $4^{\text {th }}$ week follow up $(\mathrm{p}>0.05)$. Repeated measure ANOVAs analysis indicated that no statistically significant mean difference was found between baseline systolic blood pressure to $1^{\text {st }}$ follow up, $1^{\text {st }}$ to $2^{\text {nd }}$ and $2^{\text {nd }}$ to $3^{\text {rd }}$ week follow up within the group $(p>0.05)$, however, statistically significant mean difference was found between $3^{\text {td }}$ and $4^{\text {th }}$ and $4^{\text {th }}$ to $5^{\text {th }}$ week follow up $(\mathrm{p}<0.05)$. But no statistically significant mean difference was found between group- $\mathrm{A}$ and group $=\mathrm{B}$ at different level of follow up $(p>0.05)$. Same pattern of diastolic blood pressure was noticed in different phases of follow up. 


\section{Discussion:}

This study was done to assess the clinical changes related to oral methotrexate therapy in the treatment of lichen planus. In the present study, the mean age of all the study participants was $33.9( \pm 12.4)$ years with a range of 18 to 61 years. It also showed that $30(56.8 \%)$ of the study subjects were within 25-44 years age group. Kachhawa et al. and Khondker et al. stated that lichen planus affected the middle-aged adults, which was consistent with this study $^{7,8}$.

This study revealed that male $16(36.4 \%)$ and female $28(63.6 \%)$ were affected which was similar to the report made by Katta that the prevalence of lichen planus was slightly higher in women ${ }^{1}$. In this study considering the site of lesion, skin $44(100 \%)$ involved but mucous membrane $19(43.2 \%)$, nail $10(22.7 \%)$ and hair follicle $3(6.8 \%)$ involved, clinical presentation macule, papule and plaque was found to be high among the group-B (38.1\%) compared to group-A but papule and plaque was found to be high among group-A (73.9) than group-B (57.1\%). Although, these findings were not consistent with Daoud and Pittlekow (2008) who reported that mucous membrane involvement occured in approximately 60 to $70 \%$ of patients with lichen planus ${ }^{2}$. Smaller sample size did not give conclusive epidemiological result. In the present study it was happened that smaller sample size was the cause of this dissimilarity.

The mean duration of disease was $18.7( \pm 4.0)$ months for group-A and $17.5( \pm 5.6)$ months for group-B. But the mean difference was not statistically significant $(\mathrm{p}>0.05)$. Efficacy of both drugs were measured to assay the improvement of mucocutaneous lesions, to change the colour of the lesions which became violaceous to postinflammatory hyperpigmentation, remission of itching, disappearance of existing lesions and stop appearance of new lesion.

During follow up of the patients, it was found that $95.7 \%$ of the lesion became macule treated by oral methotrexate and only $28.6 \%$ became macule treated by betamethasone oral mini- pulse. At the end of follow up, no patient had plaque among the group- $\mathrm{A}$, whereas $4.8 \%$ had plaque in group-B and the difference was statistically significant $(\mathrm{p}<0.05)$ (Table-III)

Considering the colour changes, initially $91.3 \%$ in group- $\mathrm{A}$ and $90.5 \%$ in group-B had violaceous colour and no statistically significant difference was found between two groups of patients $(\mathrm{p}>0.05)$. But at the end of $12^{\text {th }}$ week follow up, $95.7 \%$ in the group-A became post inflammatory hyper pigmentation and it was $85.7 \%$ in the group-B and $14.3 \%$ still have erythematous colour in group-B and only $4.3 \%$ of the group-A had erythematous cololur. However, analysis did not show any statistically significant difference between two groups of patients ( $>0.05)$ (Table-IV). In this study regarding complaints of itching, initially $4.3 \%$ of the group-A had complaints of mild itching and $14.3 \%$ in group-B. However, $65.2 \%$ of the group-A had severe itching and $71.2 \%$ had severe itching in group-B. At the end of $12^{\text {th }}$ week follow up, $82.6 \%$ had no complaints of itching in group-A and no patient had complaints of itching in group-B (Table V). But the difference was not statistically significant $(p>0.05)$. Remission of itching in group-B was noticed from the first follow-up ( $1^{\text {st }}$ week) but it was statistically significant on 2 nd and 6 th week $(\mathrm{p}<0.05)$. Betamethasone has got anti-inflammatory as well as anti-pruritic effect. So, it effectively reduces the symptoms of itching in lichen planus. Al-Mutairi et al. (2005) reported that itching subsided completely with the first pulse of betamethasone which is consisted with this study. But methotrexate reduces the symptom of itching very slowly and it starts to reduce from $4^{\text {th }}$ week and complete remission dose not occur. Mild itching is present in $17.4 \%$ of patients (Table-V). Al-Mutairi et al. reported that itching subsided completely with the first pulse of betamethasone which was consisted with this study. At the end of the present study, it was found that complete remission was occurred in $16(69.6 \%)$ patients in group-A, whereas 10 $(47.6 \%)$ patients among the control. Data showed that moderate remission was found $5(21.7 \%)$ patients among the group-A, but $6(28.6 \%)$ patients in the group-B, and 
the partial remission was higher among the group-B $(23.8 \%)$ compared to group-A (8.7\%). However, analysis did not reveal any statistically significant difference between two treatment modalities $(\mathrm{p}>0.05)$. Turan et al. stated that complete remission was achived in $90.9 \%$ of patients, but in this study it was achived $69.6 \%$, which was not consisted with that study ${ }^{10}$. Turan et al. used methotrexate $15 \mathrm{mg} /$ week and long duration but in this study it was used $10 \mathrm{mg} /$ week and short duration (12 weeks). So the result in this study was inconsistent with that study. In this study methotrexate was used $10 \mathrm{mg} /$ week because at low doses orally $(7.5 \mathrm{mg}$ to $10 \mathrm{mg}$ weekly) bioavailability was similar to that of parenteral administration. With increasing doses, however, absorption decreased by as much as $30 \%$ at doses of $15 \mathrm{mg}$ or greater. This study was a short duration and complete follow up were not possible due to study limitation.

In this study, clinical examination to evaluate the major adverse effects showed that in group-A, none developed anaemia and edema in subsequent follow up but $12(57.1 \%)$ patients in control group develoed edema. Body weight increased in group-A from $55.9( \pm 2.4)$ to $56.5( \pm 2.4)$ and group-B from $58.7( \pm 2.6)$ to $61.5( \pm 2.5)$. Mean difference of body weights was found between group- $\mathrm{A}$ and group- $\mathrm{B}(\mathrm{p}<0.05)$ indicating mean body weight increased in group-B compared to group-A. Al-Mutairi $\mathrm{N}$ et al. stated that edema and weight gain was the major adverse effect of betamethasone ${ }^{9}$. This study also showed the similar scenario.

Adverse clinical symptoms like diarrhea, nausea, headache, alopecia and fatigue developed in both groups of patients during follow up period. The percentages of complications were found to be higher among group-B compared to group-A, but the difference was not statistically significant $(p>0.05)$ into two groups of patients. Dyspepsia developed in group-A 11(47.8\%), but in group-B $15(71.4 \%)$. Statistically significant difference was found between two groups of patients $(\mathrm{p}<0.05)$. Hye $\mathrm{MA}^{2}$ showed that betamethasone caused dyspepsia in $62 \%$ of patients.
Among group-A, none complained of acne, mooning face and striae from baseline to follow up period. But among group-B acne 10(47.6\%), mooning face $8(38.1 \%)$ and striae $8(38.1 \%)$ developed during the follow up period. Statistically significant difference was found between two groups of patients $(\mathrm{p}<0.05)$. Hye $\mathrm{MA}^{2}$ and Al-Mutairi $\mathrm{N}$ et al. ${ }^{9}$ showed acne developed $35.5 \% \& 42.9 \%$ and mooning face developed $49.2 \%$ \& $37.5 \%$ which corresponded with this study.

Among group-A, none developed purpura and hypertrichosis from baseline to follow up period, but among group-B purpura $2(9.5 \%)$ and hypertrichosis $4(19.0 \%)$ developed during follow up period. On the contrary, mouth ulcer developed in both groups of patients during follow up. However, no statistically significant difference was found between two groups of patients $(p>0.05)$.

Among the female patients, initially none complained menstrual abnormality in both groups of patients but during follow up period, menstrual abnormality such as amenorrhoea, oligomenorrhoe, polymenorrhoea developed $5(71.54 \%)$ in group-B, but none developed menstrual abnormality among group-A. Jang N \& Fischer $\mathrm{G}^{14}$ described that methotrexate did not cause menstrual abnormality. These two findings were almost consistent with each other.

No statistically significant mean difference was found between case and control in terms of pulse rate and blood pressure at the different follow up period $(\mathrm{p}>0.05)$. Al-Mutairi $\mathrm{N}$ et al. ${ }^{9}$ and Turan $\mathrm{H}$ et al. $^{21}$ stated that betamethasone or methotrexate had no effect on cardiac function. This was consisted with this study.

\section{Conclusion:}

The clinical parameters were measured to evaluate remission of the disease and the major side effects in each follow-up of both groups of patients. The rate of complete remission is higher in group-A, than group-B.The overall adverse effects were less in group- $\mathrm{A}$, who were treated with methotrexate than group-B who were treated with 
betamethasone. So, methotrexate can be used as an alternative effective and safe drug therapy for the treatment of lichen planus.

\section{References:}

1. Katta R. Lichen planus. American Family Physician 2000; 61: 3319-324.

2. Hye MA. Lichen planus and its management: An overview. Bangladesh Journal of Dermatology, Venereology and Leprology 2006; 23(1): $12-18$.

3. Daoud MS, Pittlekow MR. Lichen planus, In: Wolff K, Goldsmith LA, Katz SI, Gilchrest BA, Paller AS and Leffell DJ. Fitzpatricks Drematology in general Medicine. $7^{\text {th }}$ ed New York: MacGraw Hill medical publishing division 2008; 244-54.

4. Breathnach SM, Black MM. Lichen planus and Lichenoid disorders, In: Burns T, Cox N and Griffiths C. Rook's Textbook of Dermatology. $7^{\text {th }}$ ed. USA: Blackwell Publishing Company 2006; 3 : 01-22.

5. Carolyn AB, Melissa IC. Methotrexate in dermatology. Dermatologic Therapy 2007; 20: 216-28.

6. Nylander LE, Wahlin YB, Hofer PA. Methotrexate supplemented with steroid ointments for the treatment of severe erosive lichen ruber. Acta Derm Venerol 2001; 82: 63-64.

7. Kachhawa D, Kachhawa V, Kalla G, Gupta L. A clinico-aetiological profile of 375 cases of lichen planus. Indian Journal of Dermatology, Venereology and Leprology 1995; 61(5): 276-79.

8. Khondker L, Wahab MA, Khan SI. Profile of lichen planus in Bangladesh. Mymensingh Medical Journal 2010; 19 (2): 400-03.

9. Al-Mutairi N, Joshi A, Zaki A, Sharma AK, Nour-Eldin O. Acute generalized lichen planus treated with weekly betamethasone 5-mg oral mini-pulse therap. Journal of Drugs in Dermatology 2005; 4(2): 218-20.

10. Buyuk AY, Kavala M. Oral metronidazole treatment of lichen planus. Journal of the American Academy of Dermatology 2000; 43(2): $260-62$.

11. Chuang TY, Stitle L, Brashear R, Lewis C. Hepatitis C virus and lichen planus: A case-control study of 340 patients. Journal of the American Academy of Dermatology 1999; 41(5): 787-89.

12. Hye MA. Pathogenesis of lichenoid tissue reactions: An immunological perspective. Bangladesh Journal of Dermatology, Venereology and Leprology 2003; 20(1): 24-30.

13. Islam MS, Islam AZMM, Islam AKMS, Wadud MA. Association of hepatitis $\mathrm{C}$ virus with lichen planus. Bangladesh Journal of Derma- tology, Venereology and Leprology 2005; 22(2): 41-47.

14. Jang N, Fischer G. Treatment of erosive vulvovaginal lichen planus with Methotrexate. Australasian Journal of Dermatology 2008; 49: 216-19.

15. Johann, EG, James, TE. Psoriasis, Fitzpatrick's dermatology in general medicine $7^{\text {th }}$ edi. McGraw-Hill Publisher, Sanfransisco, USA 2008; 169-93.

16. Lener EV, Brieva J, Schachter M, West LE, West DP, Azhary RA. Successful treatment of erosive lichen planus with topical tacrolimus, Archives of Dermatology 2001; 137: 419-22.

17. Mobini N, Toussaint S, Kamino H. Noninfectious erythematous, papular, and squamous diseases', in: Elder D, Elenitsas R and Johnson (jr), BL (editors). Lever's Histopathology of the skin, $9^{\text {th }}$ edition New York: Lippincott, Willims and Wilkins publishers, Philadelphia 2005; 179-214.

18. Passeron T, Lacour JP, Fontas E, Ortonne JP. Treatment of oral erosive lichen planus with $1 \%$ pimecrolimus cream. Archives of Dermatology 2007; 143: 472-76.

19. Sultana R, Sayeed MA. Role of different factors influencing skin and venereal diseases, Bangladesh Medical Journal (Khulna) 2002; $35(2): 52-55$.

20. Torti DC, Jorizzo JL, McCarty MA. Oral lichen planus: A case series with emphasis on therapy. Archives of Dermatology 2007; 143: 511-15.

21. Turan H, Baskan EB, Tunali S, Yazici S, Saricaoglu H. Methotrexate for the treatment of generalized lichen planus. Journal of the American Academy of Dermatology 2009; 60(1): 164-66.

22. Warren RB, Griffiths CEM. The potential of pharmacogenetics in optimizing the use of methotrexate for psoriasis. British Journal of Dermatology 2005; 153: 869-73.

23. Wolverton SE. Systemic corticosteroids. Comprehensive Dermatologic Drug Therapy. $3^{\text {rd }}$ edition: W. B. Saunders company publisher, Philadelphia 2001; 109-46.

24. Zakrzewska JM, Chan ESY, Thornhill MH. A systematic review of placebo-controlled randomized clinical trials of treatments used in oral lichen planus. British Journal of Dermatology 2005; 153: $336-41$.

25. Cribier B, Frances C, Chosidow O. Treatment of lichen planus: An evidence-based medicine analysis of efficacy. Archives of Dermatology 1998; 134: 1521-530.

26. Waller DG, Renwick AG, Hiller K. Corticosteroids (glucocorticoids and mineralocorticosteroids), in: Medical Pharmacology and Therapeutics 2001. BW Saunders, Edinburgh; 150-66. 